Polymer Journal, Vol. 39, No. 3, pp. 220-229 (2007)

(C) 2007 The Society of Polymer Science, Japan

\title{
Preparation of Amphiphilic Polysilsesquioxane by Grafting of Block Copolymer of Acrylamide Monomers
}

\author{
Toyoshi Masuda, ${ }^{1}$ Shin-ichi Yamamoto, ${ }^{1}$ Osamu Moriya, ${ }^{1, \dagger}$ \\ Mikihiro KASHIO, ${ }^{2}$ and Toshio SUGIZAKI ${ }^{2}$ \\ ${ }^{1}$ Department of Applied Chemistry, National Defense Academy, Hashirimizu, Yokosuka 239-8686, Japan \\ ${ }^{2}$ Research Laboratory, Lintec Co., Nishiki-cho, Warabi 335-0005, Japan
}

(Received October 3, 2006; Accepted December 10, 2006; Published January 24, 2007)

\begin{abstract}
The polysilsesquioxane having dithiocarbamate groups was utilized for the graftation of $N$-isopropylacrylamide (NIPAM) and $N, N$-dimethylacrylamide (DMAA) under thermal polymerization conditions. The controlled graft polymerization through RAFT process proceeded effectively to give several kinds of block copolymer of NIPAM and DMAA without formation of gel product, in which the sequence and the number of the monomer units were changed. The introduction of the block copolymers provided an amphiphilic property to the polysilsesquioxane. The hydrophilic property, which was shown as solubility in water and contact angle, was affected by the sequence and the number of the monomer units in the graft chain. Furthermore, as the expected property due to a hydrophobic aggregation of NIPAM units, the contact angles of the grafted polysilsesquioxanes measured at $60^{\circ} \mathrm{C}$ were larger than those at $23^{\circ} \mathrm{C}$. [doi:10.1295/polymj.PJ2006126]

KEY WORDS Amphiphilic Polysilsesquioxane / N-Isopropylacrylamide / RAFT Process / Graft Polymerization /
\end{abstract}

Recently, various investigations on oligomeric and polymeric silsesquioxanes, which stress on the modifications by various organic functional groups, have been presented from the interests in a useful hybrid material. ${ }^{1-9}$ As an effective procedure for the modifications of the silsesquioxanes, the graft polymerization from polysiloxane backbone is nominated. ${ }^{10-16}$ This procedure enables to provide the additional functions based on the polymeric components without loosing the essential properties of inorganic polysiloxane backbone such as durability for heat and weatherability. We also have investigated on the graft polymerizations from polysilsesquioxanes, which intended to develop the new multi-functional hybrid materials. ${ }^{17-19}$ As an example of such graftings, the introduction of copolymer of $\mathrm{N}, \mathrm{N}$-dimethylacrylamide (DMAA) and $N$-isopropylacrylamide (NIPAM) was reported in the previous work. ${ }^{20}$ The obtained polysilsesquioxane derivative successfully showed amphiphilicity and thermoresponsive phase separation. The investigations concerning the later property caused by polymerized NIPAM (polyNIPAM) have been widely developed and various applications are proposed such as microencapsulation, biosensor, and drug delivery. ${ }^{21-25}$ Such facts support the expectation that the polysilsesquioxane, combined the inorganic polysiloxane backbone with the thermoresponsive and amphiphilic graft chains, will be a candidate for high performance hybrid materials. ${ }^{26-28}$

Our previous grafting was conducted through free radical polymerization by the use of mercapto groups on the polysilsesquioxane backbone. ${ }^{20}$ In the use of the procedure, the graft chain was essentially consisted of the random copolymer of NIPAM with DMAA (polyNIPAM-ran-polyDMAA) and the number of introduced monomer units was limited because of inactivation of radical species during the polymerization. On the other hand, the investigations on such functional polymer are progressed into a new stage with the development of living polymerization techniques. The use of reversible addition-fragmentation chain transfer (RAFT) process is a representative example and contributes to prepare the designed copolymers involving polyNIPAM for practical usages. ${ }^{29-32}$ The living polymerization technique also promises the altered formation of our previous polysilsesquioxane derivative having the thermoresponsive grafted copolymer, the sequence and molecular weight of which are controlled. Especially, the hydrophobic polysilsesquioxane backbone generally needed more hydrophilic components such as polyDMAA besides polyNIPAM to show an amphiphilic property. ${ }^{20}$ Such requirement led us to the consideration that the sequence and the number of the monomer units in the block copolymers were the important factors to extend the investigation to the designed polysilsesquioxanes. Therefore, we have continuously studied on the preparation of the polysilsesquioxane having the controlled polymeric components as the graft chains.

The polysilsesquioxane having $N, N$-dimethyldithio-

${ }^{\dagger}$ To whom correspondence should be addressed (Tel: +81-46-841-3810, Ext. 2404, Fax: +81-46-844-5901, E-mail: moriyaos@nda.ac.jp). 

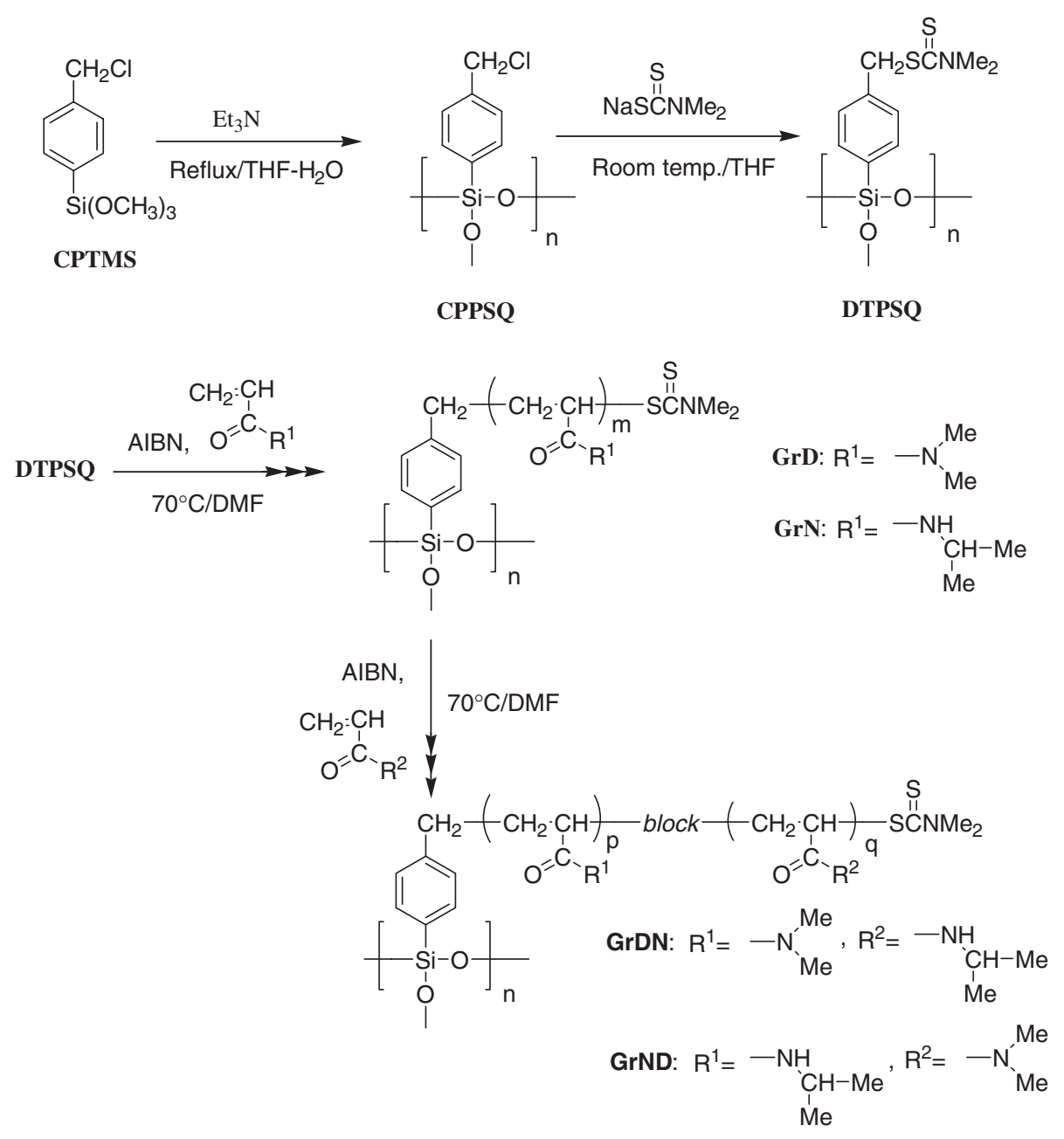

Scheme 1.

carbamate (DTC) groups (DTPSQ) was synthesized and employed for RAFT process to prepare several kinds of polysilsesquioxane containing the copolymer of NIPAM and DMAA (polyNIPAM-block-polyDMAA or polyDMAA-block-polyNIPAM), which showed the different sequence and the number of the monomer units. Then, in this primary report, we focus on the amphiphilic property presented by the graft chains. The promising property of thermoresponsive phase separation has been left as a next theme to be examined and the results will be presented near future. The synthetic routes to the block copolymer grafted polysilsesquioxanes were shown in Scheme 1.

\section{EXPERIMENTAL}

\section{General}

${ }^{1} \mathrm{H}$ NMR and ${ }^{13} \mathrm{C}$ NMR spectra were obtained on a JEOL AL-300 and JNM A-500 spectrometer in $\mathrm{CDCl}_{3}$ or DMF- $d_{7}$. IR spectra were recorded on a JASCO FT/IR 230. Gel permeation chromatographic (GPC) analysis was carried out to estimate number-average molecular weight $\left(M_{\mathrm{n}}\right)$ and polydispersity $\left(M_{\mathrm{w}} / M_{\mathrm{n}}\right)$ on a Shimadzu LC-10VP chromatograph equipped with an evaporative light scattering detector. Three columns such as Shim-pack GPC-80MD, -804D, and -802D were connected in series and $N, N$-dimethylformamide (DMF) was used as an eluent. Calibration was performed using poly(methyl methacrylate) standards. DMF employed for the reactions was refluxed over calcium hydride and distilled. Ethanol was treated with sodium and magnesium metal before use. Tetrahydrofurane (THF) was refluxed over sodium metal before use. NIPAM was recrystallized from the mixed solvent of benzene and $n$-hexane. DMAA was distilled over calcium hydride before use. $N, N^{\prime}$-Azobisisobutyronitrile (AIBN) was recrystallized from methanol. Other reagents including (4chloromethyl)phenyltrimethoxysilane (CPTMS, TCI, $98 \%$ ), and $\mathrm{N}, \mathrm{N}$-dimethyldithiocarbamic acid sodium salt dihydrate (TCI, 98\%) were used as supplied from commercial sources.

Preparation of Polysilsesquioxane Having Chloromethylphenyl Groups (CPPSQ)

CPPSQ was obtained from CPTMS by the modi- 
fied method reported before, where THF was used instead of toluene. ${ }^{18}$ The $M_{\mathrm{n}}$ and $M_{\mathrm{w}} / M_{\mathrm{n}}$ estimated by GPC were almost in accord with the previous results. The content of chloromethylphenyl group and yield were calculated from the corresponding peak areas due to the protons of methylene group bonded to benzene ring observed in ${ }^{1} \mathrm{H}$ NMR spectrum, in which hexamethyldisiloxane was used as an internal standard. The yield of CPPSQ was estimated to be 68\%; IR (KBr) 3393 (weak, OH), 3050 (weak, - $\mathrm{C}_{6} \mathrm{H}_{4}$-), 1497 (medium), 1398 (medium), 1269 (medium), 1130 (strong, Si-O), 911 (medium), 704 (medium) $\mathrm{cm}^{-1}$; ${ }^{1} \mathrm{H}$ NMR $\left(300 \mathrm{MHz}, \mathrm{CDCl}_{3}\right) \delta 4.59$ (br， Cl- $\mathrm{CH}_{2}-$ $\mathrm{C}_{6} \mathrm{H}_{4}-$ ), 6.50-7.80 (br m, $-\mathrm{C}_{6} \underline{\mathrm{H}}_{4-}$ ); ${ }^{13} \mathrm{C}$ NMR (75.45 $\left.\mathrm{MHz}, \mathrm{CDCl}_{3}\right) \delta 46.5\left(\mathrm{Cl}-\mathrm{CH}_{2}-\mathrm{C}_{6} \mathrm{H}_{4}-\right), 128.8\left(-\underline{\mathrm{C}}_{6} \mathrm{H}_{4}-\right)$, $135.2\left(-\underline{\mathrm{C}}_{6} \mathrm{H}_{4}-\right) ;$ chloromethylphenyl group $=4.81$ mmol equiv. $/ \mathrm{g}, M_{\mathrm{n}}=4000, M_{\mathrm{w}} / M_{\mathrm{n}}=1.15$.

\section{Preparation of Polysilsesquioxane Having DTC Groups (DTPSQ)}

A solution of CPPSQ (10.00 g, $48.1 \mathrm{mmol}$ equiv./ g) and $N, N$-dimethyldithiocarbamic acid sodium salt dihydrate $(9.66 \mathrm{~g}, 53.9 \mathrm{mmol})$ in THF $(50 \mathrm{~mL})$ was stirred at ambient temperature for $20 \mathrm{~h}$. The solution was evaporated under reduced pressure and the residue was diluted with methanol. The precipitated product was collected and washed with water and methanol. The resulting solid was dried at room temperature for $24 \mathrm{~h}$ in a vacuum oven under reduced pressure $(<5 \mathrm{mmHg})$ to obtain DTPSQ $(12.55 \mathrm{~g}, 99 \%$ conversion to DTC group). The contents of DTC group was calculated from the peak areas observed in ${ }^{1} \mathrm{H}$ NMR spectrum, in which hexamethyldisiloxane was used as an internal standard; IR ( $\mathrm{KBr}) 3429$ (weak, OH), 3050 (weak, $\mathrm{C}_{6} \mathrm{H}_{5}$ ), 2924 (weak, $\mathrm{CH}_{3}$ ), 1497 (medium), 1376 (medium), 1256 (medium), 1128 (strong, Si-O), 982 (medium), 706 (medium) $\mathrm{cm}^{-1} ;{ }^{1} \mathrm{H}$ NMR $\left(300 \mathrm{MHz}, \mathrm{CDCl}_{3}\right) \delta 3.29$ (br, $-\mathrm{N}-\mathrm{CH}_{3}$ ), 3.48 (br, -N$\mathrm{C}_{3}$ ), 4.43 (br, $-\mathrm{C}_{2}-\mathrm{C}_{6} \mathrm{H}_{4}-$ ), 6.50-7.80 (br m, $-\mathrm{C}_{6} \underline{\mathrm{H}}_{4}$ ); ${ }^{13} \mathrm{C}$ NMR $\left(75.45 \mathrm{MHz}, \mathrm{CDCl}_{3}\right) \delta 41.5\left(-\mathrm{N}_{-} \mathrm{CH}_{3}\right), 42.5$ $\left(-\mathrm{N}-\underline{\mathrm{CH}}_{3}\right), 45.3\left(-\mathrm{CH}_{2}-\mathrm{C}_{6} \mathrm{H}_{4}-\right), 128.7\left(-\underline{\mathrm{C}}_{6} \mathrm{H}_{4}-\right), 130.4$ $\left(-\underline{\mathrm{C}}_{6} \mathrm{H}_{4}-\right), 196.5(-\underline{\mathrm{C}}=\mathrm{S}) ;$ DTC group $=3.79 \mathrm{mmol}$ equiv. $/ \mathrm{g} ; M_{\mathrm{n}}=4500, M_{\mathrm{w}} / M_{\mathrm{n}}=1.40$.

\section{Typical Procedure for Grafting of First Monomer onto DTPSQ}

A solution of DTPSQ $(0.08 \mathrm{~g}, 0.30 \mathrm{mmol}$ equiv. of dithiocarbamate group), DMAA $(0.59 \mathrm{~g}, 6.00 \mathrm{mmol})$, and AIBN $(0.008 \mathrm{~g}, 0.05 \mathrm{mmol})$ in the mixed solvents of DMF $(1.5 \mathrm{~mL})$ and ethanol $(0.5 \mathrm{~mL})$ was introduced into a glass tube. The mixture was purged of air via three vacuum-argon cycles. Then, the mixture in the glass tube was heated at $70^{\circ} \mathrm{C}$ for $8 \mathrm{~h}$ under argon atmosphere. The resulting solution was evaporated under reduced pressure to concentrate and the residue was poured into diethyl ether. The insoluble solid was collected and dried at room temperature for $24 \mathrm{~h}$ under reduced pressure $(<5 \mathrm{mmHg})$ to obtain the polyDMAA grafted polysilsesquioxane (GrD2) (0.58g, $87 \%$ yield based on weight). The contents of DTC group and the monomer units in GrD2 were calculated from the peak areas observed in ${ }^{1} \mathrm{H}$ NMR spectrum, in which hexamethyldisiloxane was used as an internal standard; IR (KBr) 3304, 2972, 2933, 1645 $(\mathrm{C}=\mathrm{O}), 1563,1466,1132,798,729 \mathrm{~cm}^{-1} ;{ }^{1} \mathrm{H}$ NMR (DMF- $\left.d_{7}, 500 \mathrm{MHz}\right) \delta 1.30-1.80$ (br m, $-\mathrm{CH}_{2}-$ ), 2.252.70 (br, $\left.-(\mathrm{C}=\mathrm{O})-\mathrm{C} \underline{\mathrm{H}}-,-\mathrm{C}_{2}-\mathrm{C}_{6} \mathrm{H}_{4}-\right), 2.70-3.05$ (br m, $\left.-\mathrm{N}-\mathrm{CH}_{3}\right), 3.31$ (br, $\left.-(\mathrm{C}=\mathrm{S})-\mathrm{N}-\mathrm{CH}_{3}\right), 3.48$ (br, $-(\mathrm{C}=\mathrm{S})-$ $\left.\mathrm{N}-\mathrm{CH}_{3}\right), 7.10-7.80\left(\mathrm{br},-\mathrm{C}_{6} \underline{\mathrm{H}}_{4}-\right) ;{ }^{13} \mathrm{C} \mathrm{NMR}(125 \mathrm{MHz}$, DMF- $\left.d_{7}\right) \delta 35.7 \quad\left(-\mathrm{CH}_{2}-\right), 36.1$ (-다-), $37.3(-\mathrm{N}-$ $\left.\underline{\mathrm{CH}}_{3}\right), 127.8\left(-\mathrm{C}_{6} \mathrm{H}_{4}{ }^{-}\right), 131.5\left(-\mathrm{C}_{6} \mathrm{H}_{4}-\right), 133.9\left(-{ }_{6} \mathrm{H}_{4}-\right)$, $174.4(-\underline{\mathrm{C}}=\mathrm{O}) ; M_{\mathrm{n}}=42000, M_{\mathrm{w}} / M_{\mathrm{n}}=2.80 ;$ DTC group $=0.35 \mathrm{mmol} \quad$ equiv. $/ \mathrm{g} ; \quad$ DMAA $\quad$ unit $=9.1$ mmol equiv./g.

Typical Procedure for Grafting of Second Monomer

A solution of GrD2 $(0.41 \mathrm{~g}, 0.18 \mathrm{mmol}$ equiv. of DTC group), NIPAM $(0.20 \mathrm{~g}, 1.77 \mathrm{mmol})$, and AIBN $(0.005 \mathrm{~g}, 0.03 \mathrm{mmol})$ in the mixed solvents of DMF $(0.6 \mathrm{~mL})$ and ethanol $(0.2 \mathrm{~mL})$ was treated in a similar manner as mentioned in the preparation of GrD2. The insoluble solid in diethyl ether was collected as the polysilsesquioxane grafted by polyDMAA-blockpolyNIPAM (GrD2N, $0.56 \mathrm{~g}, 92 \%$ yield based on weight); IR (KBr) 3447 (N-H), 2972, 2933, 1636 $(\mathrm{C}=\mathrm{O}), 1508,1458,1139$ (Si-O-Si) cm ${ }^{-1}$; ${ }^{1} \mathrm{H}$ NMR $\left(\mathrm{CDCl}_{3}, 300 \mathrm{MHz}\right) \delta 1.08$ (br m, $\left.-\underline{\mathrm{CH}}_{3}\right), 1.30-1.80$ (br m, $-\underline{\mathrm{CH}}_{2}-$ ), 2.25-2.70 (br, $\left.-(\mathrm{C}=\mathrm{O})-\mathrm{C} \underline{\mathrm{H}}-\right), 2.70$ 3.05 (br m, $\left.-\mathrm{N}-\mathrm{CH}_{3}\right), 3.31$ (br, $\left.-(\mathrm{C}=\mathrm{S})-\mathrm{N}-\underline{\mathrm{C}}_{3}\right), 3.48$

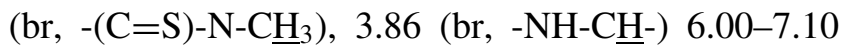
(br, $-\mathrm{C}_{6} \underline{\mathrm{H}}_{4}-,-\mathrm{NH}-$ ); ${ }^{13} \mathrm{C}$ NMR $\left(125 \mathrm{MHz}, \mathrm{DMF}-d_{7}\right) \delta$ $22.5\left(-\underline{\mathrm{CH}}_{3}\right), 35.6\left(-\mathrm{C}_{2}-\right), 36.7$ (- $\left.\underline{\mathrm{CH}}-\right), 37.2\left(-\mathrm{N}-\underline{\mathrm{CH}}_{3}\right)$, 42.3 (-NH-CHH-), $128.5\left(-\underline{\mathrm{C}}_{6} \mathrm{H}_{4}-\right), 134.1\left(-\underline{\mathrm{C}}_{6} \mathrm{H}_{4}-\right)$, $174.6(-\underline{\mathrm{C}}=\mathrm{O}) ; M_{\mathrm{n}}=53000, M_{\mathrm{w}} / M_{\mathrm{n}}=2.05 ;$ DTC group $=0.26 \mathrm{mmol} \quad$ equiv. $/ \mathrm{g} ; \quad$ DMAA unit $=5.9$ mmol equiv./g; NIPAM unit $=3.0 \mathrm{mmol}$ equiv. $/ \mathrm{g}$.

Analogously, several grafted polysilsesquioxanes having polyNIPAM-block-polyDMAA and polyDMAA-block-polyNIPAM were prepared by changing the feed mole ratio and sequence of the monomers. Furthermore, the polysilsesquioxane having polyNIPAM-ran-polyDMAA (GrRD2N) was prepared under the similar conditions by adding the monomers at once.

\section{Graft Polymerization of NIPAM for Verification of RAFT Process}

For the time-conversion, time- $\ln \left\{[\mathrm{M}]\left[/\left[\mathrm{M}_{0}\right]\right\}\right.$, and the conversion $-M_{\mathrm{n}}$ curves, the graft polymerization of NIPAM to DTPSQ $\left(M_{\mathrm{n}}=5400\right.$, DTC group $=$ 
$3.48 \mathrm{mmol}$ equiv./g) was carried out under the similar conditions as mentioned above. In the polymerization, $0.07 \mathrm{~g}$ of DTPSQ (DTC group $=0.24 \mathrm{mmol}$ equiv.), 40 equiv. of NIPAM $(1.09 \mathrm{~g}, 9.63 \mathrm{mmol})$ to DTC group, and AIBN $(0.01 \mathrm{~g}, 0.06 \mathrm{mmol})$ in DMF (3.0 $\mathrm{mL})$ and ethanol $(1.0 \mathrm{~mL})$ were used and the samples were taken by syringe at appropriate intervals for GPC and ${ }^{1} \mathrm{H}$ NMR analysis. The results were shown in Figures 3-5.

\section{Measurement of Contact Angle}

A solution of the grafted polysilsesquioxane $(0.05 \mathrm{~g})$ in THF $(5 \mathrm{~mL})$ was cast on poly(ethylene terephthalate) sheet $(150 \mathrm{~mm} \times 200 \mathrm{~mm})$ and, then, THF was removed by heating at $80^{\circ} \mathrm{C}$ for $1 \mathrm{~min}$ in an oven. The resulting film of the grafted polysilsesquioxane showed $c a .200 \mathrm{~nm}$ thickness. The static contact angle was measured on the coated film with deionized water drops at $23^{\circ} \mathrm{C}$ and $60^{\circ} \mathrm{C}$ by a Krüss DSA100 Automatic Contact Angle Meter, in which relative humidity was kept to be $50 \%$ and the observation was conducted within $10 \mathrm{~s}$. The measurement was performed three times for a sample. The average angles of the observed values were listed in Table III.

\section{Measurement of Transmittance (\%T) for Solubility in Water}

$1 \mathrm{wt} \%$ solution of the grafted polysilsesquioxane in deionized water was used for the measurement of transmittance (\%T) on a Shimadzu UV-1650 spectrophotometer equipped with a Peltier-type S-1700 thermostatic cell holder, where the changes of $\% \mathrm{~T}$ were observed from a visible source at $600 \mathrm{~nm}$ through a $1 \mathrm{~cm}$ quartz sample cell during heating and cooling scans. The rate of heating and cooling was adjusted to be $1{ }^{\circ} \mathrm{C} / 1 \mathrm{~min}$. The cycle of heating and cooling was repeated three times for a sample, in which almost same curves indicating the thermoresponsive behavior were observed. The value indicating solubility in water was the $\% \mathrm{~T}$ observed at $20^{\circ} \mathrm{C}$.

\section{RESULTS AND DISCUSSION}

\section{Preparation of CPPSQ and DTPSQ}

By the method reported before, the condensation of CPTMS in the presence of $5 \mathrm{~mol} \%$ of triethylamine was carried out under reflux conditions in the mixed solvents of THF and water. ${ }^{18}$ CPPSQ was obtained from methanol as an insoluble solid in 63\% yield, which was based on the content of chloromethyl group estimated by the ${ }^{1} \mathrm{H}$ NMR spectral data mentioned below. Next, the reaction of CPPSQ with $\mathrm{N}, \mathrm{N}$-dimethyldithiocarbamic acid sodium salt dihydrate was carried out at ambient temperature in THF solution. The substitution reaction proceeded readily

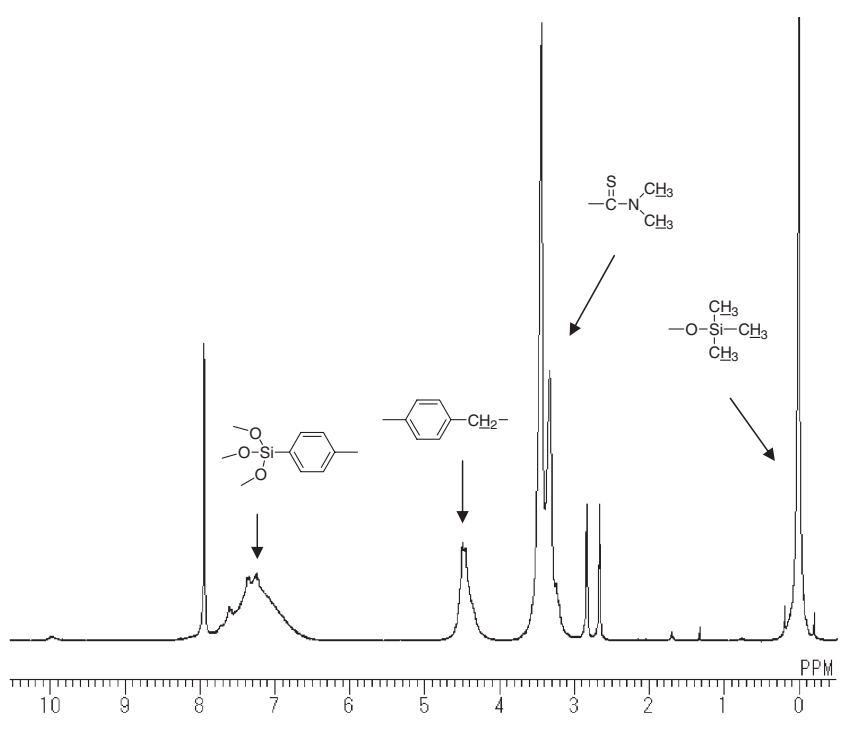

Figure 1. ${ }^{1} \mathrm{H}$ NMR spectrum (DMF- $d_{7}, 300 \mathrm{MHz}$ ) of DTPSQ with hexamethyldisiloxane as an internal standard.

to afford the polysilsesquioxane having $N, N$-dimethyldithiocarbamate groups as an insoluble solid in methanol. The ${ }^{1} \mathrm{H}$ NMR spectral data showed the quantitative introduction of DTC group.

The contents of chloromethylphenyl and DTC group were estimated by the proton ratios observed in the ${ }^{1} \mathrm{H}$ NMR spectrum. In the measurements, hexamethyldisiloxane was used as an internal standard, the signal of which appeared at $0 \mathrm{ppm}$. The spectrum of DTPSQ was shown in Figure 1. The signal assigned to the protons of methylene group bonded to benzene ring was observed at $4.59 \mathrm{ppm}$ in the spectrum of CPPSQ. In the spectrum of DTPSQ, the corresponding signal was shifted to 4.43 ppm by changing chlorine to DTC group. The contents of chloromethyl and DTC group were calculated from the peak areas of these easily distinguishable signals. From the estimation, CPPSQ was shown to contain $4.81 \mathrm{mmol}$ equiv./ $\mathrm{g}$ of chloromethyl group. After the reaction, the signal at $4.59 \mathrm{ppm}$ was disappeared completely and the presence of $3.28 \mathrm{mmol}$ equiv./g of DTC group in DTPSQ was calculated. The calculation indicated that chlorine in CPPSQ was converted almost quantitatively to DTC group in DTPSQ. Furthermore, the signals at 3.29 and $3.48 \mathrm{ppm}$ were newly observed, which were assigned to methyl protons of DTC group.

Other spectral data such as ${ }^{13} \mathrm{C}$ NMR and IR also supported the formation of CPPSQ and DTPSQ. In the IR spectra of CPPSQ and DTPSQ, the presence of silicon-oxygen bond was shown by the strong absorbance at $1100 \mathrm{~cm}^{-1}$. In the ${ }^{13} \mathrm{C}$ NMR spectrum of DTPSQ, the carbon of introduced methyl groups bonded to nitrogen was detected at 41.5 and 42.5 ppm. The carbon of methylene attached to benzene ring was observed at $46.5 \mathrm{ppm}$ in the case of CPPSQ. 


\section{T. MASUDA et al.}

Table I. Preparation of grafted polysilsesquioxane ${ }^{\mathrm{a}}$

\begin{tabular}{|c|c|c|c|c|c|c|c|}
\hline \multirow{2}{*}{$\begin{array}{l}\text { 1st Monomer } \\
\text { (Feed mole ratio } \\
\text { to DTC group) }\end{array}$} & \multirow{2}{*}{$\begin{array}{l}\text { 2nd Monomer } \\
\text { (Feed mole ratio } \\
\text { to DTC group) }\end{array}$} & \multirow{2}{*}{$\begin{array}{c}\text { Product } \\
\left.\text { (Yield }^{\mathrm{b}}, \%\right)\end{array}$} & \multirow{2}{*}{$\begin{array}{c}M_{\mathrm{n}}\left(M_{\mathrm{w}} / M_{\mathrm{n}}\right) \\
\text { estimated by } \\
\mathrm{GPC}^{\mathrm{c}}\end{array}$} & \multicolumn{2}{|c|}{$\begin{array}{c}\mathrm{DP}^{\mathrm{d}} \text { of } 1 \mathrm{st} \\
\text { monomer block }\end{array}$} & \multicolumn{2}{|c|}{$\begin{array}{c}\mathrm{DP}^{\mathrm{d}} \text { of } 2 \mathrm{nd} \\
\text { monomer block }\end{array}$} \\
\hline & & & & $\mathrm{GPC}^{\mathrm{c}}$ & $\mathrm{NMR}^{\mathrm{e}}$ & $\mathrm{GPC}^{\mathrm{c}}$ & $\mathrm{NMR}^{\mathrm{e}}$ \\
\hline DMAA (10) & - & GrD1 (94) & $22000(2.74)$ & 10.4 & 11.0 & - & - \\
\hline - & NIPAM (10) & GrD1N (91) & $43000(2.55)$ & 10.4 & 11.0 & 10.9 & 10.3 \\
\hline DMAA (20) & - & GrD2 (87) & $42000(2.80)$ & 22.2 & 26.0 & - & - \\
\hline- & NIPAM (10) & GrD2N (92) & $53000(2.05)$ & 22.2 & 22.7 & 7.1 & 11.5 \\
\hline DMAA (30) & - & GrD3 (92) & $55000(2.13)$ & 29.9 & 33.3 & - & - \\
\hline - & NIPAM (10) & GrD3N (92) & $66000(1.83)$ & 29.9 & 31.9 & 7.0 & 10.0 \\
\hline NIPAM (10) & - & GrN (86) & $23000(2.39)$ & 10.2 & 10.3 & - & - \\
\hline - & DMAA (10) & GrND1 (87) & $47000(2.51)$ & 10.2 & 10.0 & 13.3 & 12.4 \\
\hline - & DMAA (20) & GrND2 (92) & $58000(2.20)$ & 10.2 & 10.7 & 21.0 & 21.7 \\
\hline - & DMAA (30) & GrND3 (99) & $64000(2.07)$ & 10.2 & 10.0 & 30.8 & 33.3 \\
\hline DMAA (20) & - & GrRD2N (91) & $55000(2.03)$ & - & 20.7 & - & - \\
\hline NIPAM (10) & - & - & - & - & - & - & 10.3 \\
\hline
\end{tabular}

${ }^{\text {a } T h e ~ p o l y s i l s e s q u i o x a n e ~ D T P S Q, ~} M_{\mathrm{n}}$ of which was estimated to be 4500 , contained $3.79 \mathrm{mmol}$ eq./g of DTC group. The polymerization was conducted in the presence of $17 \mathrm{~mol} \%$ of AIBN to DTC group at $70^{\circ} \mathrm{C}$ for $18 \mathrm{~h}$ in the mixed solvents of DMF and ethanol, in which the concentration of the monomer was adjusted to be $2.3[\mathrm{M}] .{ }^{\mathrm{b}}$ The yield was based on the weights of the substrates. ${ }^{\mathrm{c}}$ Estimated by GPC with poly(methyl methacrylate) standards, in which DMF was used as an eluent. ${ }^{\mathrm{d}}$ Degree of polymerization. ${ }^{\mathrm{e}}$ The content was based on ${ }^{1} \mathrm{H}$ NMR spectral data.

This was shifted to $45.3 \mathrm{ppm}$ in the spectrum of DTPSQ. The estimated $M_{\mathrm{n}}$ and $M_{\mathrm{w}} / M_{\mathrm{n}}$ of CPPSQ by GPC were $c a .4000$ and 1.15 , respectively. After the reaction, the $M_{\mathrm{n}}$ of DTPSQ was estimated to be the somewhat larger value such as 4500 . The obtained CPPSQ and DTPSQ were soluble in chloroform, acetone, THF, and DMF, but insoluble in $n$-hexane and methanol. By taking into the consideration of the spectral data and solubility in the usual organic solvents, the obtained polysilsesquioxanes CPPSQ and DTPSQ were supposed to contain a ladder- and an incomplete cage-like polysiloxane structures, although these have been still unidentified.

\section{Grafting of Copolymer of NIPAM and DMAA onto DTPSQ}

In the preliminary experiments, the grafting of homopolymer of NIPAM from DTPSQ was conducted under UV irradiation, in which DTC group was regarded as a photoiniferter. Although the grafting progressed efficiently without formation of gel product, the content of DTC group in the obtained polysilsesquioxane derivative was estimated to be about $75 \%$ of the initial one. This was inadequate to prepare the well controlled block copolymers as the graft chains. Therefore, the grafting of the copolymer was examined under thermal-polymerization conditions, where the polymerization was expected to proceed through RAFT process. In various reports concerning the RAFT process, the use of thioester, dithioester, and trithiocarbonate compounds is shown to be effective for chain transfer reaction. These reagents are usually obtained as the phenyl and alkyl derivatives. ${ }^{33-36}$ In the application of such chain transfer groups to our polysilsesquioxane derivative, we presumed the difficulty to estimate the content of the groups from the peak areas observed in the corresponding ${ }^{1} \mathrm{H}$ NMR spectrum. Since, the signals, which indicate the presence of the group and the grafted polymers, usually show the analogous chemical shifts. On the other hand, $\mathrm{N}, \mathrm{N}$-dimethyldithiocarbamate group was thought to be an appropriate group. The characteristic signals due to methyl protons of DTC group were detected in the distinguishable region from those due to polymeric DMAA and NIPAM. In addition, as mentioned above, the introduction of the group could be readily achieved by the simple substitution reaction. From such reasons, DTC group was employed for the controlled graft polymerizations by RAFT process.

The polymerization was carried out at $70^{\circ} \mathrm{C}$ in the presence of AIBN, the amount of which was adjusted to be $17 \mathrm{~mol} \%$ to DTC groups. In the polymerizations, the concentration of the monomer was fixed to be $c a .2 .5[\mathrm{M}]$ in the mixed solvents of DMF and ethanol. The results were listed in Table I. In the both cases using DMAA and NIPAM as the first monomer, the grafted polysilsesquioxanes GrDs and GrN were obtained in the high yields over $86 \%$ and no crosslinked product was detected in the products. The $M_{\mathrm{n}} \mathrm{s}$ estimated by GPC analyses were 22000 for GrD1, 42000 for GrD2, and 55000 for GrD3, in which the numbers of the monomer unit were estimated to be 10, 22, and 30 for one DTC group, respectively. The $M_{\mathrm{n}} \mathrm{s}$ increased with the content of the 


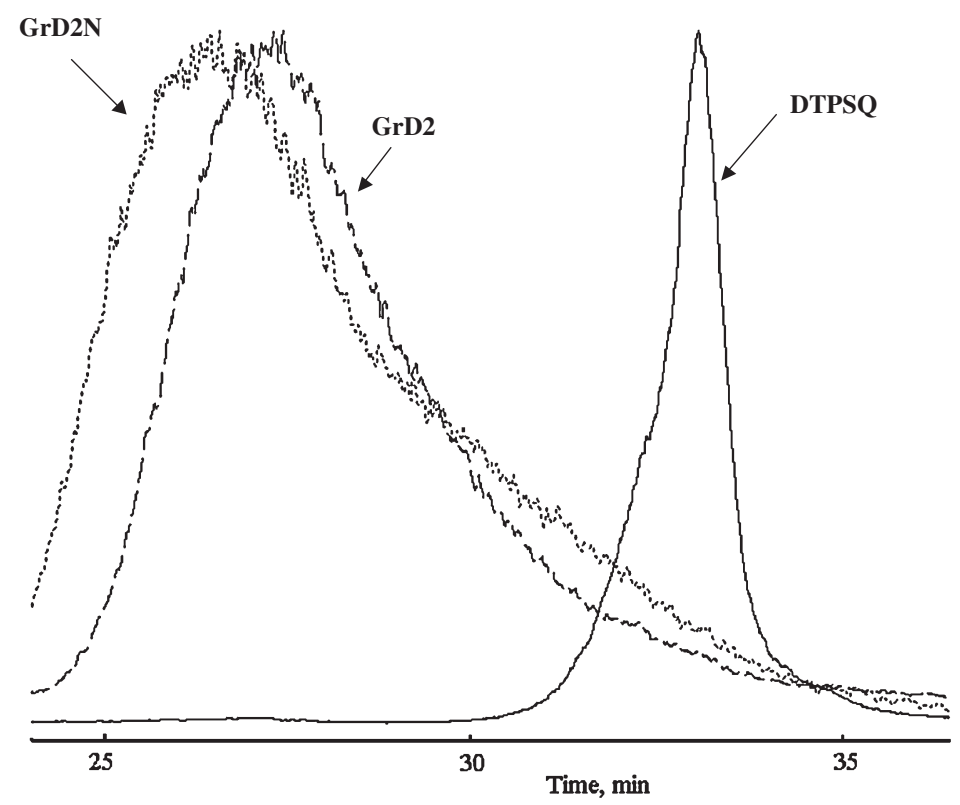

Figure 2. GPC chromatogram of (-) DTPSQ, (---) GrD2, and ( $\cdots)$ GrD2N.

monomer units as expected. The polydispersities of GrDs were in the range from 2.13 to 2.80 . The $M_{\mathrm{n}}$ of $\mathbf{G r N}$, intended to introduce 10 equiv. of NIPAM units to DTC group, showed the similar value such as 23000 to that estimated for GrD1 which contained ca. 10 equiv. of DMAA unit. In the application of RAFT process under thermal polymerization conditions, almost quantitative amount of DTC groups was recovered after the first grafting of DMAA or NIPAM. The degree of polymerization (DP) based on GPC essentially reflected the feed mole ratio of the monomers, although somewhat larger values of DP were estimated in the ${ }^{1} \mathrm{H}$ NMR analyses for GrD2 and GrD3. The polysilsesquioxanes introducing the first monomer units were isolated as the insoluble parts in diethyl ether and, then, employed for the further grafting.

The graft polymerization of the second monomer to obtain the block copolymer as the graft chains also proceeded effectively. In this work, the feed mole ratio of NIPAM was fixed to be 10 equivalents to DTC group. The introductions of polyNIPAM to GrDs and polyDMAA to GrN proceeded to give the polysilsesquioxanes having the block copolymers in over $87 \%$ yield. The $M_{\mathrm{n}} \mathrm{s}$ of the resulting polysilsesquioxanes increased in comparison with those of the polysilsesquioxanes having the first monomer units. In addition, the polysilsesquioxane having polyNIPAM-ran-polyDMAA (GrRD2N) was prepared under the same conditions by single step polymerization. GrRD2N was obtained in $91 \%$ yield and showed the analogous $M_{\mathrm{n}}$ such as 55000 to those of GrD2N and GrND2.

In the chromatograms of GPC for the grafted polysilsesquioxanes, a unimodal peak was observed.

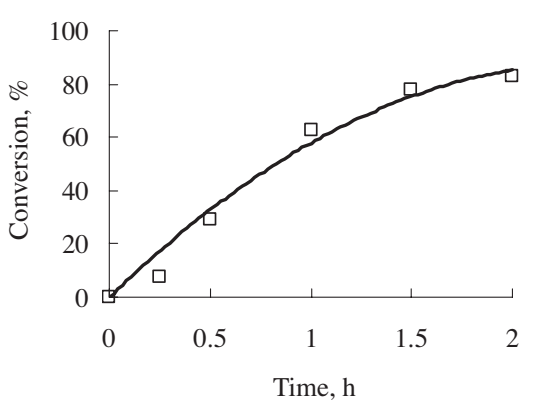

Figure 3. Relationship between time and conversion in the polymerization using 40 equiv. of NIPAM to DTC group in DMF and ethanol.

For the examples, the chromatograms of DTPSQ, GrD2, and CrD2N were shown in Figure 2. The increases of $M_{\mathrm{n}} \mathrm{s}$ through the grafting of the second monomer seemed to be reasonable except for the cases of $\mathbf{G r D}_{\mathbf{2}} \mathbf{N}$ and $\mathbf{G r D}_{3} \mathbf{N}$. In these cases, the DPs based on the ${ }^{1} \mathrm{H}$ NMR analyses showed the presence of $c a$. 10 equiv. of NIPAM unit to DTC group as expected from the feed mole ratio. However, the DPs calculated from the changes of $M_{\mathrm{n}} \mathrm{s}$ were the insufficient values such as $c a$. 7 . This may indicate the presence of homopolymer of NIPAM. To obtain the information concerning this possibility, the graft polymerization of NIPAM to DTPSQ was independently examined. The time-conversion, time- $\ln \left\{\left[\mathrm{M}_{0}\right] /[\mathrm{M}]\right\}$, and conversion- $M_{\mathrm{n}}$ curves of the polymerization were shown in Figures 3-5, respectively. In the use of 40 equiv. of NIPAM to DTC group, the values of conversion increased with the reaction time reasonably (Figure 3) and the linear relationship of $\ln \left[\mathrm{M}_{0}\right] /[\mathrm{M}]$ with time was observed (Figure 4). In addition, the 


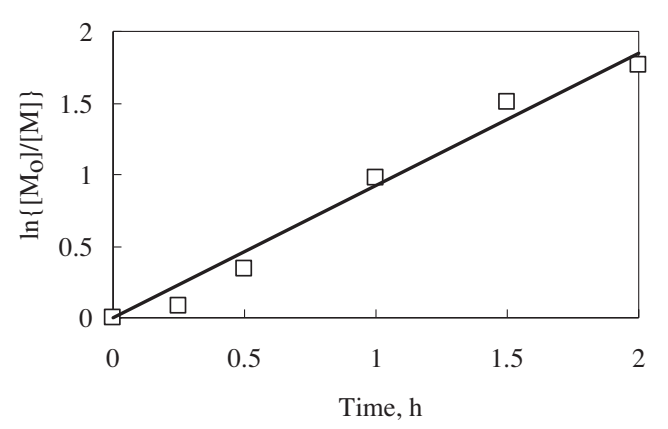

Figure 4. Relationship between time and $\ln \left\{\left[\mathrm{M}_{0}\right] /[\mathrm{M}]\right\}$ in the polymerization using 40 equiv. of NIPAM to DTC group in DMF and ethanol. $\left[\mathrm{M}_{0}\right]$ is the initial monomer concentration and $[\mathrm{M}]$ is the monomer concentration.

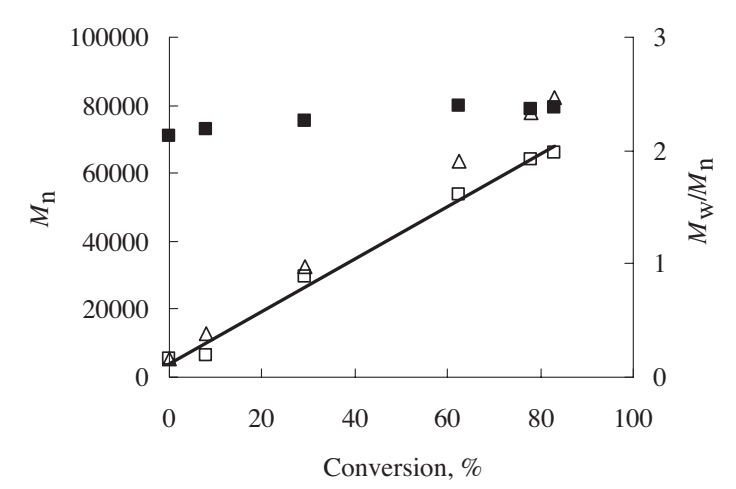

Figure 5. Relationships between conversion and $(\square) M_{\mathrm{n}},(\triangle)$ theoretical $M_{\mathrm{n}}$, or (匹) $M_{\mathrm{w}} / M_{\mathrm{n}}$ in the polymerization using 40 equiv. of NIPAM to DTC group in DMF and ethanol.

$M_{\mathrm{n}}$ of the grafted polysilsesquioxane also increased linearly according to the increase of conversion (Figure 5). Such observations supported the speculation that the polymerization proceeded living fashion under the conditions adopted in this work. However, in the relationship between conversion- $M_{\mathrm{n}}$, the line gradually deviated from that on the basis of theoretical values. Namely, the experimental values of $M_{\mathrm{n}}$ became smaller compared to the theoretical ones after ca. 30\% conversion. The result suggested that the DP estimated from GPC analysis appeared smaller than the real one in the grafting of NIPAM. Therefore, the observations seemed to support the interpretation that the graft polymerization progressed primarily to form the grafted derivative from DTPSQ as the main product.

The contents of DTC group and the monomer units in the graft chains, utilized for the estimations of DP, were based on ${ }^{1} \mathrm{H}$ NMR spectral data. As an example, the ${ }^{1} \mathrm{H}$ NMR spectrum of GrD2N was shown in Figure 6. In the ${ }^{1} \mathrm{H}$ NMR spectrum of GrD2, the signals due to the protons of methylene and methine groups were detected in the range from 1.2-2.5 ppm. The signals due to the protons of benzene ring were

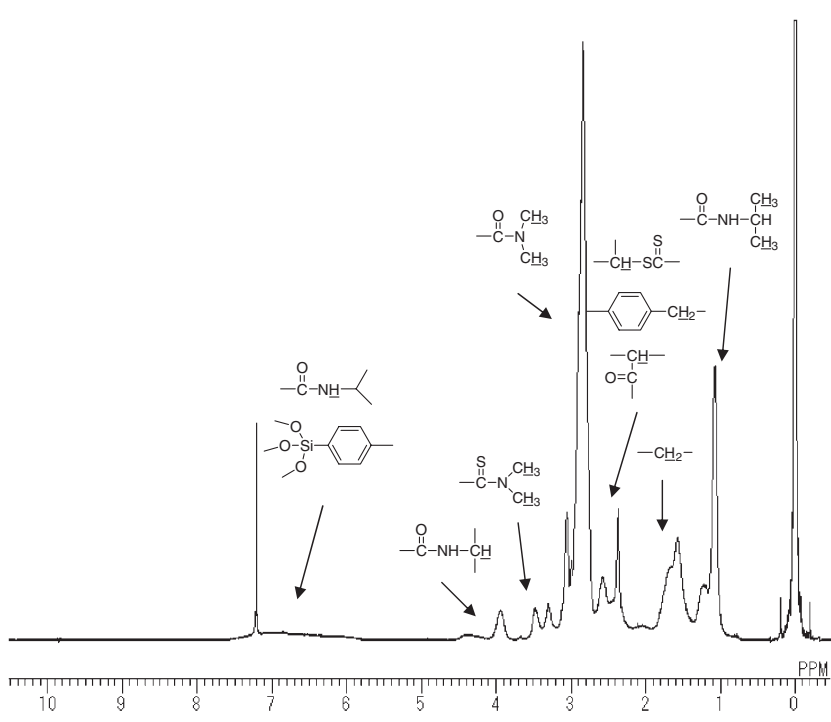

Figure 6. ${ }^{1} \mathrm{H}$ NMR spectrum (DMF- $\left.d_{7}, 300 \mathrm{MHz}\right)$ of GrD2N with hexamethyldisiloxane as an internal standard.

appeared at $7.2 \mathrm{ppm}$. The protons of two methyl groups of DMAA unit were appeared as a broad signal at $c a .2 .84 \mathrm{ppm}$. The analogous methyl protons of DTC group were assigned to two signals observed at 3.31 and $3.48 \mathrm{ppm}$. The peak areas of those signals were employed for the calculation of the contents of DMAA unit and DTC group. The further introduction of NIPAM units was confirmed by the characteristic signals. The signal newly observed at $1.08 \mathrm{ppm}$ was assigned to the methyl protons of isopropyl group of NIPAM units. A distinguishable signal was detected at $3.86 \mathrm{ppm}$ due to the methine proton bonded to nitrogen. This was convenient for the calculation to determine the content of NIPAM unit. In addition, a broad peak, overlapped with those due to benzene ring, was appeared at $7 \mathrm{ppm}$. The peak was assigned to the proton attached to nitrogen of NIPAM unit. The mole ratios of DTC group, DMAA unit, and NIPAM unit in the grafted polysilsesquioxanes were estimated by the peak areas mentioned above. The estimated ratios were almost in accord with the prospected ones based on the feed mole ratios of the substrates. However, the content of DMAA unit may be inaccurate because of the difficulty to detect the clearly distinguishable signals for the unit. The ratios of the units based on ${ }^{1} \mathrm{H}$ NMR spectral data were listed in Table II.

${ }^{13} \mathrm{C}$ NMR spectrum of the grafted polysilsesquioxanes also supported the incorporations of the graft chains. The signals observed at $22.46 \mathrm{ppm}$ due to methyl carbon demonstrated the presence of isopropyl group of NIPAM unit. Other signals at 37.2 and 42.3 ppm were assigned to the carbons of methyl and methine groups bonded to nitrogen of polymerized DMAA and NIPAM unit, respectively. The carbon of amide groups of both NIAPM and DMAA unit ob- 
Table II. ${ }^{1} \mathrm{H}$ NMR analysis of grafted polysilsesquioxane ${ }^{\mathrm{a}}$

\begin{tabular}{|c|c|c|c|}
\hline Product & $\begin{array}{l}\text { Content of } \\
1 \mathrm{st} \\
\text { monomer } \\
\text { unit }^{\mathrm{c}} \\
\text { mmol eq. } / \mathrm{g} \\
\end{array}$ & $\begin{array}{l}\text { Content of } \\
\text { 2nd } \\
\text { monomer } \\
\text { unit }^{\mathrm{c}} \\
\text { mmol eq. } / \mathrm{g}\end{array}$ & $\begin{array}{c}\text { Content of DTC } \\
\text { group }^{\mathrm{c}} \\
\text { mmol eq./g } \\
\text { (Remained } \\
\text { group, \%) }\end{array}$ \\
\hline GrD1 & 7.9 & - & $0.72(93)$ \\
\hline GrD1N & 4.1 & 3.8 & $0.37(>99)$ \\
\hline GrD2 & 9.1 & - & $0.35(83)$ \\
\hline GrD2N & 5.9 & 3.0 & $0.26(85)$ \\
\hline GrD3 & 9.0 & - & $0.27(87)$ \\
\hline GrD3N & 6.7 & 2.1 & $0.21(91)$ \\
\hline GrN & 7.2 & - & $0.70(94)$ \\
\hline GrND1 & 3.4 & 4.2 & $0.34(96)$ \\
\hline GrND2 & 2.9 & 6.3 & $0.29(97)$ \\
\hline GrND3 & 2.1 & 7.0 & $0.21(80)$ \\
\hline GrRD2N & 6.0 & 3.0 & 0.29 \\
\hline
\end{tabular}

${ }^{\mathrm{a}}$ The content was based on ${ }^{1} \mathrm{H}$ NMR spectral data measured with hexamethyldisiloxane as an internal standard.

served as a signal appeared at $174.6 \mathrm{ppm}$. Furthermore, the presence of the monomer units in the grafted polysilsesquioxanes was demonstrated in the IR spectra. In the spectra, a strong absorbance at 1640 $\mathrm{cm}^{-1}$ due to amide group and that at $1100 \mathrm{~cm}^{-1}$ assigned to silicon-oxygen bond of the polysiloxane backbone were obviously observed.

Thus, the polysilsesquioxanes listed in Table I, which showed the different sequences and numbers of DMAA and NIPAM units in the graft chains, were prepared efficiently by the use of RAFT technique, in which no gelation was observed. The facts indicated that the DTC group on polysilsesquioxane was usable in RAFT process and enabled the controlled introduction of the acrylamide polymers as the graft chains. Furthermore, the main peak was appeared as a unimodal one in the chromatogram of the GPC measurements for the grafted polysilsesquioxanes except for a few cases, in which a small peak was detected in the region indicating an extraordinary molecular weight.

\section{Hydrophilic Property of the Grafted Polysilsesqui- oxanes}

The introduction of copolymer of NIPAM and DMAA was an effective procedure to transform the hydrophobic polysilsesquioxane to the hydrophilic one as reported previously. Especially, the grafting of DMAA units contributed to provide an amphiphilic property. ${ }^{17}$ The fact suggests that the location of DMAA units in the graft chain is an important factor to change the property of the polysilsesquioxane derivative. Namely, when polyDMAA chains are placed near the hydrophobic polysilsesquioxane backbone, its solubility in water is expected to be improved more effectively. To obtain the information which supports such speculation, the effect of sequence of the monomer units on the property was evaluated by contact angle and the transmittance of $1 \mathrm{wt} \%$ aqueous solution of the grafted polysilsesquioxanes.

For the measurement of contact angle, the coated film of the grafted polysilsesquioxanes on polyethylene terephthalate sheet was used. The results were listed in Table III. At first, the contact angle of water drop on the surface of the film was measured at $23^{\circ} \mathrm{C}$ within 10 s. The starting polysilsesquioxane CPPSQ was enough hydrophobic as shown in the angle such as $98^{\circ}$ compared to the polyethylene terephthalate sheet, which showed $74^{\circ}$ of contact angle. ${ }^{17}$ The angle decreased remarkably to be $20^{\circ}$ by grafting of polyDMAA-block-polyNIPAM as observed in the case of GrD2N. The analogous values of $24^{\circ}$ and $22^{\circ}$ were recorded in the measurement for GrRD2N containing polyNIPAM-ran-polyDMAA and GrND2 containing polyNIPAM-block-polyDMAA, respectively. These samples were consisted of the same molar ratios and the number of the monomer units to GrD2N. In the cases of GrD3N and GrND3, the contact angles were also in the range from $21^{\circ}$ to $23^{\circ}$. The results demonstrated that the grafting of the hydrophilic polymeric components brought about the obvious decrease of the contact angle. However, no effect of the sequence and the number of the monomer units in the graft chains was observed. This may indicate that the graft chains randomly surround the polysilsesquioxane backbone in the film and/or are too short to show the influence of the end monomer units of the graft chains.

Next, the measurement for the contact angle was conducted at $60^{\circ} \mathrm{C}$, where a change of angle was presumed as reported in the previous study of the hybrid

Table III. Contact angle of grafted polysilsesquioxane ${ }^{a}$

\begin{tabular}{|c|c|c|c|c|c|c|c|}
\hline \multirow[b]{2}{*}{ Temperature } & \multicolumn{7}{|c|}{ Grafted polysilsesquoxane } \\
\hline & GrD1N & GrD2N & GrD3N & GrND1 & GrND2 & GrND3 & GrRD2N \\
\hline $23^{\circ} \mathrm{C}$ & $38^{\circ}$ & $20^{\circ}$ & $23^{\circ}$ & $35^{\circ}$ & $21^{\circ}$ & $21^{\circ}$ & $24^{\circ}$ \\
\hline $60^{\circ} \mathrm{C}$ & $68^{\circ}$ & $66^{\circ}$ & $54^{\circ}$ & $70^{\circ}$ & $66^{\circ}$ & $59^{\circ}$ & $28^{\circ}$ \\
\hline
\end{tabular}

${ }^{\text {a }}$ The static contact angle was measured for the coated film of the grafted polysilsesquioxane on polyethylene terephthalate sheet with deionized water drop. The relative humidity was kept to be $50 \%$ during the measurement and the observation was performed within $10 \mathrm{~s}$. 


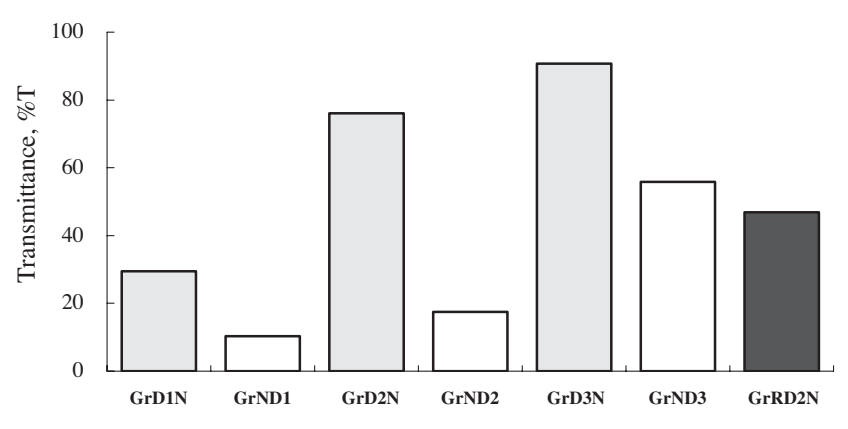

Figure 7. Optical transmittance $(600 \mathrm{~nm})$ of $1 \mathrm{wt} \%$ aqueous solution of the grafted polysilsesquioxane at $20^{\circ} \mathrm{C}$.

of silica and polyNIPAM. ${ }^{37}$ In the case of GrD2N, the value of $20^{\circ}$ at $23^{\circ} \mathrm{C}$ changed to $66^{\circ}$ at $60^{\circ} \mathrm{C}$. For other samples, the contact angles of $\mathrm{ca} .20^{\circ}$ at $23^{\circ} \mathrm{C}$ increased to over $54^{\circ}$ with the raise of temperature to $60{ }^{\circ} \mathrm{C}$. When the measurements were made once again at the lower temperature, the contact angles of the samples showed the values near $20^{\circ}$. The results were interpreted that a hydrophobic aggregation of polyNIPAM occurred even in the films of the grafted polysilsesquioxanes at $60^{\circ} \mathrm{C}$ and disaggregation progressed by lowering the temperature to $23^{\circ} \mathrm{C}$. In the case of GrRD2N, no change of the contact angle with the rise of temperature was observed as expected. The coil-globule transition of GrRD2N having polyNIPAM-ran-polyDMAA was observed around $80^{\circ} \mathrm{C}$. Therefore, the aggregation, resulted in the increase of contact angle, could not be observed at $60^{\circ} \mathrm{C}$. Such thermoresponsive behavior of the grafted polysilsesquioxanes will be reported in near future as mentioned above. Thus, the results suggested that the property of thermoresponsive phase separation was maintained even in the coating films of the grafted polysilsesquioxanes.

Contrary to the results of the measurements of contact angle, the solubility of the grafted polysilsesquioxanes in water was affected obviously by the sequence of the monomer units. The transmittances of the grafted polysilsesquioxanes at $20^{\circ} \mathrm{C}$ were shown in Figure 7. The $\% \mathrm{~T}$ of GrD2N was $75 \%$ and that of GrND2 was $18 \%$. On the other hand, GrRN2D showed the moderate $\% \mathrm{~T}$ such as $50 \%$. The analogous tendency was recorded in the combination of GrD1N and GrND1. The \% $\mathrm{T}$ of the former sample, containing DMAA units near the polysilsesquioxane backbone, was $30 \%$. However, the lower $\% \mathrm{~T}$ such as $10 \%$ was recorded in the case of GrND2, which sandwiched NIPAM units between the backbone and DMAA units. The facts indicated that the position of DMAA units was an important factor to provide a hydrophilic property to the hydrophobic polysilsesquioxane. Namely, the hydrophilic DMAA units placed near the polysilsesquioxane backbone im- proved the solubility in water efficiently. When polyDMAA was located as the end units in the graft chain, the effect of the hydrophilic units on the solubility of the grafted polysilsesquioxane in water was reduced. In addition, the transmittances of GrD3N and GrND3 reasonably showed the higher values of $\% \mathrm{~T}$ than those of GrD2N and GrND2, respectively.

\section{CONCLUSIONS}

The polysilsesquioxane having DTC groups was employed for the grafting of block copolymer of NIPAM and DMAA through RAFT process. The results demonstrated that the effective graft polymerization by the use of DTC group under thermal-polymerization conditions proceeded without formation of cross-linked product. By the grafting procedure, the block copolymers showing several kinds of sequence and number of the monomer units were successfully introduced onto the polysilsesquioxane backbone. Such designed grafted derivatives of polysilsesquioxane were provided an amphiphilic property by the grafted polymeric components.

The sequence and number of the monomer units in the graft chains affected on the solubility of the polysilsesquioxane in water. The hydrophilic polyDMAA located near the polysilsesquioxane backbone, as shown in the cases of GrDNs, reduced the hydophobicity due to the polysilsesquioxane backbone effectively. However, when polyNIPAM was placed between the polysilsesquioxane backbone and polyDMAA as shown in the series of GrNDs, such role to improve the solubility in water was insufficient. The solubility of the polysilsesquioxanes GrRD2N, containing polyNIPAM-ran-polyDMAA, in water was middle of GrD2N and GrND2.

In the measurements of contact angle, the grafted polysilsesquioxane was shown to keep the property of thermoresponsive phase separation even in the film. Such reversible thermoresponsive behavior of the polysilsesquioxane derivative as a multi-functional hybrid is under investigation now, in which the information mentioned above should be helpful.

\section{REFERENCES}

1. R. H. Baney and X. Cao, "In Silicon-Containing Polymers," R. G. Johns, W. Ando, and J. Chojnowski, Ed., Kluwer, Dordrecht, 2000.

2. M. M. Sprung and F. O. Guenther, J. Polym. Sci., 28, 17 (1958).

3. J. F. Brown Jr, L. H.Vogt Jr, A. Katchman, J. W. Eustance, K. M. Kaiser, and K. W. Krantz, J. Am. Chem. Soc., 82, 6194 (1960).

4. D. A. Roy and K. J. Shea, Chem. Rev., 95, 1409 (1995).

5. T. Kondo, K. Yoshi, K. Horie, and M. Itoh, Macro- 
molecules, 33, 3650 (2000).

6. J.-K. Lee, K. Char, H.-W. Rhee, H. W. Ro, D. Y. Yoo, and D. Yoon, Polymer, 42, 9085 (2001).

7. S. Yamamoto, N. Yasuda, A. Ueyama, H. Adachi, and M. Ishikawa, Macromolecules, 37, 2778 (2004).

8. C.-L. Chang and C.-C. M. Ma, J. Polym. Sci., Part A: Polym. Chem., 41, 1371 (2003).

9. P. S. G. Krishnan and C. He, Macromol. Chem. Phys., 204, 531 (2003).

10. J. Pyun and K. Matyjaszewski, Chem. Mater., 13, 3436 (2001).

11. K.-M. Kim, D.-K. Keum, and Y. Chujo, Macromolecules, 36, 867 (2003).

12. K. Suzuki, J. Oku, M. Takai, H. Okabayashi, and C. J. O'Connor, Polym. J., 35, 938 (2003).

13. G. Cardoen and E. B. Coughlin, Macromolecules, 37, 5123 (2004).

14. B. X. Fu, A, Lee, and T. S. Haddad, Macromolecules, 37, 5211 (2004).

15. K. Ohno, S. Sugiyama, K. Koh, Y. Tsujii, T. Fukuda, M. Yamahiro, H. Oikawa, Y. Yamamoto, N. Ootake, and K. Watanabe, Macromolecules, 37, 8517 (2004).

16. T. Zhang, K. X. Hong Chen, and X. Yu, J. Appl. Polym. Sci., 91, 190 (2004).

17. O. Moriya, S. Yamamoto, S. Kumon, T. Kageyama, A. Kimura, and T. Sugizaki, Chem. Lett., 33, 224 (2004).

18. T. Sugizaki, M. Kashio, A. Kimura, S. Yamamoto, and O. Moriya, J. Polym. Sci., Part A: Polym. Chem., 42, 4212 (2004).

19. S. Yamamoto, T. Shimada, A. Kimura, T. Sugizaki, and O. Moriya, Polym. J., 36, 761 (2004).

20. O. Moriya, M. Kuga, S. Yamamoto, M. Kashio, A. Kamejima, and T. Sugizaki, Polymer, 47, 1837 (2006).

21. J. E. Guillet, J. Macromol. Sci. Chem., A2, 1441 (1968).
22. G. H. Chen and A. S. Hoffman, Nature, 373, 49 (1995).

23. B. Ray, Y. Isobe, K. Matsumoto, S. Habaue, Y. Okamoto, M. Kamigaito, and M. Sawamoto, Macromolecules, 37, 1702 (2004).

24. S. Meyer and W. Richtering, Macromolecules, 38, 1517 (2005).

25. K. S. Kim and B. Vincent, Polymer, 37, 565 (2005).

26. M. Anthonietti, S. Förster, J. Hartmann, and S. Oestreich, Macromolecules, 29, 3800 (1996).

27. M. Sciborek, N. K. Gladkova, and J. Chojnowski, Polym. Bull., 44, 377 (2000).

28. H. Kudo, M. Yamamoto, T. Nishikubo, and O. Moriya, Macromolecules, 39, 1759 (2006).

29. M. Arotçaréna, B. Heise, S. Ishaya, and A. Laschewsky, J. Am. Chem. Soc., 124, 3787 (2002).

30. M. Nuopponen, J. Ojala, and H. Tenhu, Polymer, 45, 3643 (2004).

31. Q. Liu, P. Zhang, and M. Lu, J. Polym. Sci., Part A: Polym. Chem., 43, 2615 (2005).

32. A. J. Convertine, B. S Lokitz, Y. Vasileva, L. J. Myrick, C. W. Scales, A. B. Lowe, and C. L. McCormick, Macromolecules, 39, 1724 (2006).

33. M. Destarac, D. Charmot, X. Franck, and S. Z. Zard, Macromol. Rapid Commun., 21, 1035 (2000).

34. J. Chiefari, R. T. A. Mayadunne, C. L. Moad, G. Moad, E. Rizzardo, A. Postma, M. A. Skidmore, and S. H. Thang, Macromolecules, 36, 2273 (2003).

35. S. Perrier and P. Takolpuckdee, J. Polym. Sci., Part A: Polym. Chem., 43, 5347 (2005).

36. M. Benaglia, E. Rizzardo, A. Alberti, and M. Guerra, Macromolecules, 38, 3129 (2005).

37. G. V. Rama Rao, M. E. Krug, S. Balamurugan, H. Xu, Q. Xu, and G. P. Lòpez, Chem. Mater., 14, 5075 (2002). 